\title{
Experiências de Recuperação e o Stress Ocupacional em Psicólogos(as), no exercício da sua função
}

\section{Recovery Experiences and the Occupational Stress in Psychologists, in the exercise of its function}

\author{
José Pedro M. T. Carvalho* e Fatíma Lobo** \\ *Aluno da Universidade Católica Portuguesa / Braga - Portugal \\ **Universidade Católica Portuguesa / Braga - Portugal / Pest-OE/FIL/UIO6832015
}

\begin{abstract}
Resumo:
Esta investigação analisa a influência das experiências profissionais no stress e nas estratégias de recuperação numa amostra de Psicólogos. A literatura cientifica na área da Psicologia do Trabalho, na última década, tem revelado preocupação com os níveis de stress e as estratégias de recuperação, no sentido de promover a saúde e a qualidade de vida no trabalho. Utilizaram-se três instrumentos: o Questionário sociodemográfico; Questionário The Recovery Questionnaire e o Questionário de Stress Ocupacional Versão geral. A amostra é constituida por 230 participantes, 56 são do género masculino e 174 do feminino, com idades compreendidas entre os 20 e 65 anos. Os resultados revelam que a principal fonte de stress é "falta de possibilidade de desenvolvimento e promoção na carreira". A maioria dos profissionais afirma que procura alargar os seus horizontes e tempo para desfrutar de momentos de lazer, embora continuem a pensar no trabalho. As subescalas de Relaxamento, Procura de Desafios e o Controlo variam inversamente com os niveis de stress. A presente investigação poderá contribuir para repensar as estratégias de recuperação a nível pessoal e profissional, que proporcionem melhor qualidade de vida, e desenvolvimento de programas de intervenção nas organizações.
\end{abstract}

Palavras-Chave: Globalização, Experiências de Recuperação; Stress Ocupacional; Psicólogos (as)

\begin{abstract}
:
This research analyzes the influence of professional experience on stress and recovery strategies in a sample of psychologists. In the past decade, the scientific literature in the field of Psychology work, has revealed concerns about stress levels and recovery strategies to promote health and quality of life at work. They used three instruments: the sociodemographic questionnaire; The questionnaire Recovery Questionnaire and the Occupational Stress Questionnaire - General Version. The sample is composed by 230 participants, 56 are males and 174 females, aged between 20 and 65 years. The results show that the main source of stress is "lack of possibility of development and career promotion." Most professionals states that seeks to broaden their horizons and time to enjoy leisure time, while still thinking about work. The subscales of Relaxation, Challenges search and control vary inversely with stress levels. This research may contribute to rethink the recovery strategies personal and professional level, providing better quality of life, and development of intervention programs in organizations.
\end{abstract}

Key words: Globalization, Recovery Experiences, Ocupacional Stress, Phychologists

\section{Introdução \\ Experiências de Recuperação}

O tempo dedicado ao trabalho e ao tempo livre tem vindo a sofrer alterações com o passar dos anos, do ponto de vista social e pessoal. Ao contrário do que se pensou na década de 70 , onde se previa um aumento do tempo livre como consequência do aumento tecnológico, o que se verificou foi o oposto, o tempo dedicado ao trabalho originou uma diminuição do tempo livre (Costa, 2011).

O termo "Recuperação" advém da necessidade que o indivíduo tem de se "restabelecer" depois de ter despendido esforços e recursos internos para satisfazer as exigências que lhe são exigidas. Nos últimos anos, diferentes pesquisas destacaram o papel das experiências de recuperação no stress causado pelo trabalho no estado emocional, afetivo dos trabalhadores (Fritz, Sonnentag, Spector \& McInroe, 2010), na saúde, bem-estar e desempenho individual no trabalho (Fritz \& Sonnentag, 2005; Sonnentag \& Fritz, 2007).

De acordo com Sonnentag e Natter (2004), o esforço que nos é exigido pode causar reações de tensão, podendo comprometer tanto o bem-estar, como o desempenho, tornando assim a recuperação condição necessária para a sua proteção.

Sonnentag e Ziljstra (2006) afirmam que para ocorrer uma recuperação completa é fundamental haver períodos de recuperação entre o trabalho (estratégias diárias; noites; fins-de-semana livres e até mesmo durante as férias), sendo suficiente para anular os efeitos negativos que se acumularam ao longo do dia de trabalho, nomeadamente o stress.

A recuperação de recursos é um processo de reparação dos efeitos negativos do trabalho sobre os trabalhadores onde as capacidades dos indivíduos voltam para níveis pré-stress, níveis positivos. A recuperação é variável, há dias em que de manhã o trabalhador se sente totalmente recuperado e em outros em que o mesmo não acontece (Demerouti, Bakker, Sonnentag, \& Fullagar, 2012).

Nos períodos de descanso uma das estratégias que pode ser desenvolvida com vista à recuperação é a separação mental do trabalho, ou seja, parar de "pensar no trabalho". Existe desta forma um distanciamento com os esforços mentais e físicos. Alguns estudos concluem que 
maior distanciamento do trabalho se reflete na melhoria do humor, menor fadiga e menores distúrbios do sono e, quando regressam ao trabalho conseguem realizar de forma mais sustentada as suas atividades (Demerouti et al, 2012).

Por sua vez, Sonnentag e Fritz (2007) referem-se às experiências de recuperação como um termo que caracteriza atributos associados com atividades fora do trabalho que contribuam para a recuperação, nomeadamente, as experiências, como o distanciamento psicológico do trabalho, relaxamento, experiência de domínio e o controlo durante o tempo de lazer, entre outras. Assim, referem que o distanciamento psicológico consiste em estar fisicamente fora do local de trabalho, implicando não estar ocupado com questões relacionadas ao trabalho, tais como receber chamadas relacionadas com o trabalho no telefone em casa ou estar ativamente a envolverem-se em tarefas/experiências relacionadas com o trabalho. O relaxamento é um processo associado às atividades de lazer.

Sonnentag e Bayer (2005) realizaram um estudo que comprovou que a carga de trabalho está negativamente relacionada com o distanciamento psicológico do trabalho durante horas tardias e positivamente relacionado com bom humor e baixos níveis de fadiga. Assiste-se à dificuldade de concretizar o distanciamento psicológico. As experiências de domínio, referem-se a atividades fora do trabalho, que distraem do trabalho, fornecendo experiências desafiadoras e oportunidades de aprendizagem em outros domínios. Exemplos típicos incluem, escalar uma montanha, ou aprender um novo hobby. O controlo pode ser a capacidade que uma pessoa tem para escolher uma ação a partir de duas ou mais opções. A experiência de controlo durante o tempo de lazer pode satisfazer então, o desejo de controlo, aumentando a autoeficácia e os sentimentos de competência, que por sua vez irão promover o bemestar (Fritz \& Sonnentag, 2006).

O trabalho interfere na vida privada podendo dificultar a recuperação dos recursos. De acordo com Costa (2011) existem três grandes tipos de interferências do trabalho na vida privada. Em primeiro lugar, existe uma interferência temporal que ocorre quando o tempo dedicado ao trabalho é de tal forma absorvente que deixa praticamente de existir tempo para se dedicar às exigências da vida pessoal e familiar. Em segundo lugar, a interferência baseada na tensão do trabalho na medida em que as pressões e tensões do trabalho se transportam para a vida pessoal. Por último, as interferências comportamentais ocorrem, quando um comportamento aceitável no trabalho é transportado para a vida pessoal onde já não é aceitável.

A necessidade de recuperação manifesta-se através do desejo de "recarregar as baterias", afastandose de todas as exigências que levaram à diminuição dos recursos disponíveis que, em condições normais, são restabelecidos após esse afastamento. Quanto maior forem as exigências durante o dia de trabalho, maiores serão as necessidades de recuperação que, se não forem totalmente restabelecidas podem levar a que se inicie um novo dia de trabalho ainda com deficiências de recursos do dia anterior (Sonnentag \& Zijlstra, 2006).
O processo de recuperação tem sido estudado tendo como base três modelos fundamentais, tais como o Modelo da Conservação de Recursos de Hobfoll (Fritz \& Sonnentag, 2005), o Modelo das Exigências-Controlo (Araújo, Graça, \& Araújo, 2003) e o Modelo das Exigências-Recursos (Kuhnel \& Sonnetag, 2010).

No que diz respeito aos recursos de Hobfoll (Fritz \& Sonnentag, 2005) delimitou a dimensão como aqueles que são valorizados por uma ampla classe de indivíduos e que são percebidos como mais salientes tanto pelas pessoas em geral, assim como pelo próprio indivíduo. Os recursos podem incluir objetos, condições, características pessoais e energias que tem importância e valor específicos para o indivíduo e são valorizados para a sua sobrevivência, direta ou indiretamente, ou que servem como um meio de atingir esses recursos. Este modelo, diz-nos que as pessoas se esforçam para preservar, proteger e construir recursos e que é uma ameaça para eles a perda potencial ou real desses recursos valorizados. Estas perdas são importantes, em dois níveis: primeiro, pois os recursos têm valor instrumental para as pessoas e, segundo, porque eles têm um valor simbólico na medida em que ajudam as pessoas a definir quem elas são. Podese argumentar que os indivíduos devem usar os seus períodos de tempo fora do trabalho para reconstruir os recursos consumidos durante o período de trabalho anterior e que podem ser necessários no período laboral seguinte (Fritz \& Sonnentag, 2005). Recentes estudos com a Teoria de Conservação de Recursos demonstram os efeitos das pausas nos resultados do trabalho, na medida em que o afastamento das exigências durante uma pequena pausa permite investir em novos recursos e o restabelecimento dos já gastos. Neste sentido, o afastamento do trabalho permite a regeneração dos recursos, podendo assim também resultar numa redução das tensões e melhorar os resultados quando os indivíduos voltam ao trabalho (Fritz \& Sonnentag, 2005).

Destaca-se assim, para além de descrever o que os indivíduos fazem quando confrontados com stress, também descreve como se comportam na ausência de ameaças. Quando confrontados com situações de stress, os indivíduos lutam para minimizar a perda de recursos. Contudo, quando não se encontram em situações de tensão, os indivíduos tendem a desenvolver reservas de recursos para situações futuras que possam existir. Nestas situações, o esgotamento é descrito como o estado extremo de quebra de recursos enquanto o engagement pode ser visto como a reserva de recursos (Innstrand, Langballe, \& Falkum, 2011).

No que diz respeito ao modelo ExigênciasControlo foi elaborado por Karasek sendo uma proposta contrária aos modelos que abordam o stress no trabalho de uma forma unidimensional. Este modelo estuda simultaneamente as exigências e o controlo no trabalho (Araújo, Graça, \& Araújo, 2003).

As dimensões básicas deste modelo são: as exigências psicológicas com o trabalho e o grau de controlo. As combinações entre as dimensões revelam diferentes experiências no trabalho. As exigências são as pressões a que o trabalhador está sujeito no seu local de trabalho, nomeadamente, pressões de tempo, a concentração para o desenvolvimento das atividades 
laborais ou a dependência do trabalho de terceiros. No que se refere ao controlo este modelo refere duas componentes: os aspetos que se relacionam com a capacidade de fazer todas as tarefas, a criatividade, capacidade de aprendizagem ou o desenvolvimento de capacidades individuais.

Por outro lado, o controlo compreende a autoridade para tomar decisões sobre o trabalho e a sua influência com o restante grupo de trabalho (Araújo, Graça, \& Araújo, 2003). Os autores afirmam que, a interação entre níveis alto e baixo das exigências e do controlo geram quatro tipos de experiencias laborais, respetivamente: (1) Alta exigência no trabalho: quando existe uma grande exigência e baixo controlo; (2) Trabalho ativo: quando ambas as dimensões têm níveis altos; (3) Trabalho passivo: quando pelo contrário ambas as dimensões têm níveis baixos e (4) Baixa exigência quando se combina baixas exigências com alto controlo. Estas relações concluem, que grande parte das reações negativas às exigências do trabalho (fadiga, ansiedade, depressões ou doenças) acontece quando há grandes exigências e reduzido controlo sobre o trabalho. Por outro lado, situações de trabalho passivo podem levar à perda de capacidades para enfrentar o trabalho, menor eficiência e dificuldade em encontrar soluções para os problemas encontrados (Araújo, Graça, \& Araújo, 2003). Este modelo é atualmente um dos mais usados em estudos de saúde ocupacional, aspetos psicossociais e ao nível das consequências para a saúde do trabalhador.

O modelo das exigências-recursos (Kuhnel \& Sonnetag, 2010), é integrativo, contemplando outras teorias, como é o caso da teoria de Conservação de Recursos. O principal pressuposto do Modelo das Exigências-Recursos é que cada profissão tem os seus próprios fatores de risco associados às situações de stress no trabalho (Kuhnel \& Sonnetag, 2010). Defendendo assim, a ideia de que todas as organizações têm o seu próprio ambiente de trabalho e cada função tem as suas próprias causas para o bem-estar do trabalhador (Bakker \& Demerouti, 2007).

A nível organizacional, os fatores podem ser classificados em duas categorias: as exigências do trabalho e os recursos laborais. Segundo Kuhnel e Sonnetag (2010), as exigências do trabalho dizem respeito aos aspetos físicos, psicológicos, sociais ou organizacionais do trabalho que requerem esforços físicos e/ou psicológicos por parte do trabalhador (como por exemplo as pressões no trabalho ou horários de trabalho irregulares). Os recursos laborais, referem-se aos aspetos físicos, psicológicos, sociais ou organizacionais do trabalho que vão reduzir as exigências do trabalho e os custos que lhe estão associados, estimulando assim o crescimento, aprendizagem e o desenvolvimento organizacional (Kuhnel \& Sonnetag, 2010).

Os recursos do trabalho podem estar localizados em vários níveis da organização: ao nível macro relaciona-se com o salário, oportunidades de carreira ou a segurança para com o trabalho; a um nível interpessoal está relacionado com o clima das equipas ou suporte dos supervisores; ao nível específico do cargo ocupado, como a participação nas tomadas de decisão; e por fim ao nível da função, relacionado com as capacidades e performance (Demerouti \& Bakker, 2011).

Os mesmos salientam, um segundo pressuposto do Modelo das Exigências-Recursos é a de que existem dois processos psicológicos que atuam no desenvolvimento das "preocupações" relacionadas com o trabalho e a motivação. O primeiro processo é o de prejuízo da saúde, que sugere que trabalhos muito exigentes esgotam os recursos mentais e físicos dos trabalhadores e podem levar a situações de exaustão e problemas de saúde. O segundo processo é relacionado com a motivação em que se assume que os recursos laborais têm um potencial motivador que leva a um aumento do comprometimento com o trabalho e melhoria da performance. Os recursos podem assim levar os trabalhadores a aprender e desenvolverem as suas capacidades. O Modelo das Exigências-Recursos constitui um modelo global que pode ser aplicado a inúmeros ambientes profissionais, independentemente das exigências ou dos recursos.

O último e mais recente pressuposto, indica que os recursos laborais influenciam a motivação ou o engagement quando as exigências laborais são mais elevadas. Os recursos são mais benéficos na manutenção do engagement e da performance quando as exigências são altas, revelando atitudes de comprometimento com a organização e com as tarefas (Demerouti \& Bakker, 2011).

\section{Stress Ocupacional}

$\mathrm{O}$ conceito de stress tem vindo a ser trabalhado ao longo dos séculos, com contributos de vários autores, com o objectivo de se encontrar uma definição concreta e precisa do conceito. Desde o século XIV o termo é utilizado com o significado de constrição física sendo que, no século XX, Serra (2002) alargou o significado para pressão na mente humana, referindo ainda a existência de dois tipos de agentes stressores. Esses agentes são externos, quando originados pelo ambiente, e podem ser de natureza física (frio, calor, ruído), psicológica (conflitos interpessoais) e social (desemprego). Os agentes são internos quando originados por acontecimentos perturbadores inerentes a cada pessoa.

Presentemente, segundo Kazmi, Amjad e Khan (2008), a definição de stress mais utilizada descreve-o como um estado psicológico e físico, sucedido quando os recursos do indivíduo são insuficientes para lidarem com as pressões e consequências da situação à qual se encontram expostos. Seabra (2008) acrescenta e esclarece que o stress pode ser classificado como agudo se for limitado no tempo, ou crónico (burnout) se repetido diversas vezes, próximas no tempo. Assim, Serra (2002) apresenta-nos um modelo compreensivo do stress que a literatura aponta como o mais pertinente e esclarecedor. Neste modelo é referida como condição principal para que haja stress a presença de elementos stressores, elementos esses a que o individuo não é indiferente. As experiências desses elementos são filtradas e avaliadas individualmente, sendo que o desencadear do processo de stress depende da forma como cada pessoa enfrenta e lida com as tensões. Neste sentido, as respostas ao stress 
podem ser biológicas, comportamentais, cognitivas e emocionais. São as estratégias de coping que permitem lidar com as pressões, diminuindo o stress se forem adequadas, e/ou mantendo os níveis de stress se forem desadequadas.

O conceito de trabalho, o ritmo e a intensidade são mais visíveis e vivenciados, proporcionando mais problemas, em especial para a Psicologia do Trabalho e das Organizações, uma vez que a qualificação, a competência, a adaptabilidade, a capacidade de comunicar, de resolver problemas, o trabalho em equipa e a permanente disponibilidade para a aprendizagem, são elementos fundamentais para alcançar a eficácia laboral (Neves, 2014).

Ao serviço das organizações, entidades sociais, heterogéneas e racionalmente estruturadas, com elementos que desempenham diferentes funções em prole do alcance de fins e objectivos comuns (Canavarro \& Oliveira, 2004), são colocados indivíduos activos e interactivos dotados de características específicas (Ferreira, Neves \& Caetano, 2011). Assim, segundo Serra (2011) o trabalho deve ser visto como fonte de motivação, realização profissional e crescimento psicológico de um indivíduo, consequentes de reconhecimento profissional e social, tendo influências directas na sua auto estima e na sua identidade. Contudo, Laranjeiras (2009) diz-nos que nem sempre é exactamente assim que a relação trabalhador-organização acontece. Quando há uma discrepância evidente nesta relação alguns problemas podem surgir, e o stress ocupacional pode ser um exemplo existente em qualquer profissão e em qualquer nível hierárquico. Como tal o stress ocupacional tem recebido ultimamente uma maior atenção pela comunidade científica (Franco \& Tavares, 2009).

Rodrigues, Álvaro e Rondina (2006) dizem-nos que o mal-estar relacionado com o trabalho desencadeia desconforto psicológico, que se manifesta através da raiva, ansiedade, frustração, danos orgânicos, conflitos, absentismo entre muitos outros que, por sua vez, se reflete na produtividade organizacional. Assim sendo, surge o conceito de stress ocupacional como sendo um dos termos mais utilizados nos últimos anos devido às suas consequências a nível individual e organizacional (Vaz Serra, 2005; Bicho \& Pereira, 2007).

Bicho e Pereira (2007) dizem-nos que as fontes do stress podem ser organizacionais e extra organizacionais. As fontes de stress organizacionais são as características do trabalho, das funções e do papel desenvolvido (a ambiguidade e o conflito do papel, dificuldade de conciliar o trabalho com a família), o tipo de liderança (o estilo de liderança, objetivos não claros por parte da empresa e chefias mal preparadas, etc.), as relações de trabalho (falta de aceitação e reconhecimento do trabalhador por parte dos colegas, superiores ou subordinados), a estrutura e o clima organizacional (hierarquia, tomada de decisão, a insuficiente comunicação e a insegurança do emprego), e as condições físicas (o espaço, os recursos, a temperatura, o ruído e a falta de privacidade). As fontes extra organizacionais, por sua vez, são as situações que ocorrem ao longo da vida e do quotidiano e que, em excesso, podem produzir uma resposta fisiológica, psicológica e comportamental, tendo impacto negativo ao nível individual e organizacional. Cooper (1982, in Seabra, 2008) acrescenta que existem condições que podem ser indutoras de stress no trabalho e que estas dependem do indivíduo, da sua personalidade e aptidões para lidar com os acontecimentos. Por outro lado, Vaz-Serra (2007) afirma que se o trabalhador sentir ameaças ao nível das tarefas a desempenhar, das relações interpessoais existentes no meio laboral e ao nível das motivações inerentes ao seu empenho e desempenho nas suas funções, então o stress ocupacional vai surgir e ter repercussões fundamentais na vida de cada individuo.

Contudo, existe a dificuldade de identificar uma fonte exclusiva para o stress ocupacional. Vaz-Serra (2007) destaca a característica cumulativa patente no stress ocupacional, sendo o contexto profissional, familiar e social da pessoa refletores e influenciadores do mesmo. Perante isto, a existência de qualquer circunstância desagradável nos vários ambientes que o individuo percorre aumenta piora o grau de tolerância e o impacto negativo dos acontecimentos laborais.

Franco e Tavares (2009) dizem-nos que o sector da saúde tem recebido menos atenção dos investigadores do que os outros sectores, apesar das profissões de saúde, e em particular os técnicos de diagnóstico e terapêutica, serem consideradas de alto risco em termos de stress ocupacional.

\section{Método}

O enquadramento teórico apresentado sustenta a importância de se realizar este estudo, que tem como objetivos conhecer o stress ocupacional e as experiências de recuperação em psicólogos (as) no exercício das suas funções, verificando as relações ou correlações em função de determinadas variáveis sociodemográficas e profissionais, a relação existente entre as variáveis sociodemográficas e o stress ocupacional e experiências de recuperação; as relações entre as variáveis profissionais e o stress ocupacional e experiências de recuperação e por último verificar a existência de uma correlação entre o stress ocupacional e as experiências de recuperação. Tendo por base estas indicações gerais, esta investigação procurou atingir os seguintes objetivos especificos: a-) Estudar as Fontes de Stress Ocupacional destes profissionais de acordo com as variáveis sociodemográficas e profissionais; b-) Estudar as formas como os profissionais recuperam após o dia de trabalho; c-) Analisar a relação existente entre as fontes de stress ocupacional e as experiências de recuperação. Assim se formularam as seguintes hipóteses:

- H1: Os niveis de stress ocupacional variam em função das variáveis independentes: Género; Idade; Número de Filhos; Formação Academica; Área de Formação; Trabalha para Além do Horário Estipulado e Dimensão da Organização.

- H2: Se as variaveis sociodemográficas são preditoras das variáveis dependentes Relaxamento e Afastamento Psicológico, então quanto maior for o número de filhos, menor serão as experiências de Relaxamento e Afastamento Psicológico.

- H3: Se as experiências de recuperação (Experiências de Relaxamento, Procura de Desafios, Afastamento Psicológico e Controlo) variam em função dos niveis de 
stress, então quanto maiores forem os niveis de stress, maior será a necessidade de experiências de recuperação.

\section{Procedimento}

Após o pedido de utilização dos instrumentos aos autores e respetiva confirmação, foram contactados os Psicólogos (as) de uma instituição de tratamento de toxicodependência na cidade do Porto, por conveniência e facilidade de acesso, sendo os questionários distribuídos em mão. O questionário ficou disponível na plataforma Online Google Docs, para a população alvo Psicólogos (as) no exercício das suas funções em diversas áreas de atuação, em Portugal e Brasil. Disponível online, foi divulgado através de duas redes sociais, Facebook e LinkedIm onde foram selecionados profissionais de psicologia quer masculinos quer femininos, propondo que estes reencaminhassem o link do questionários a outros profissionais das suas relações, através do efeito "bola de neve". Foi apresentado um consentimento informado de participação no estudo e foi ao mesmo tempo garantido o anonimato dos participantes e a confidencialidade dos dados recolhidos, assegurando a sua utilização para fins. Os resultados ficarão disponíveis e acessíveis se assim os participantes o desejarem, apenas no final da investigação. A recolha decorreu entre período compreendido entre Novembro 2014 e Abril 2015. O tratamento e análise estatística foram feitos no programa Statistical for Social Sciences (SPSS, versão 21.0 para Windows), posteriormente são explicados.

\section{Instrumentos}

Foram administrados 3 questionários, $\mathrm{O}$ "Questionário sociodemográfico", criado para o efeito, avaliou variáveis tais como: género, idade, nacionalidade, estado civil, número de filhos, local de residência, formação académica, área de formação, área de especialização, situação profissional, anos de profissão, sector, horas de trabalho, regime, situação contractual e por último a dimensão da organização. A "Escala The Recovery Experience”, desenvolvida por Sonnentag, e Fritz (2007) adaptada por Lobo e Pinheiro (2012) para a população Portuguesa, composta por 16 itens, sendo respondidos numa escala tipo likert de 5 pontos $(0=$ Discordo totalmente; 5 =Concordo totalmente). Os itens distribuem-se por 4 subescalas: (1) Relaxamento (itens: $5 ; 6 ; 7 ; 8) ;(2)$ Procura de Desafios através dos itens (itens: 9;10;11;12), (3) Afastamento Psicológico através dos itens (itens: $1 ; 2 ; 3 ; 4 ; 13)$ e (4) Controlo através dos itens (itens: $14 ; 15 ; 16)$ da escala original. O "Questionário de Stress nos Profissionais de Saúde" (QSPS) (Gomes, 2010). O questionário compreende duas partes distintas. $\mathrm{Na}$ fase inicial é proposto aos profissionais a avaliação do nível global de stress experienciado na sua atividade, através de um único item, numa escala de 0 a 4 (0= Nenhum stress; 4 = Elevado stress). Na segunda parte, são apresentados 25 itens relativos às potenciais fontes de stress associados à atividade profissional. Os itens distribuem-se por 7 subescalas, (1) Relação com utentes (itens:8;13;21), (2) Relação com chefias (itens:12;20;24), (3) Relação com colegas (itens: 4;17;22), (4) Excesso de trabalho (itens:5;10,11;16), (5) Carreira e Remuneração (itens: $1 ; 6 ; 15 ; 19)$, (6) Problemas Familiares (itens:3;14;23) e (7) Condições de Trabalho (itens:
$7 ; 9 ; 18)$, sendo respondidos numa escala tipo likert de 5 pontos $(0=$ Nenhum stress; $4=$ Elevado stress $)$.

\section{Análise e descrição dos resultados}

A amostra é constituída por 230 participantes de duas nacionalidades Portugueses $(n=196)$ e Brasileiros $(n=34), 56$ participantes são do sexo masculino e 174 do sexo feminino, representando $(24,3 \%)$ e $(75,7 \%)$ da população. A idade varia entre o mínimo de 20 anos e máxima de 65 anos, sendo a amostra composta por 180 profissionais entre a faixa etária (20 anos - 40 anos) e 50 entre a faixa etária (41 anos a 65 anos), representando $(78,3 \%)$ e $(21,7 \%)$ da população. Verifica-se que 96 participantes são solteiros, 75 são casados, 24 são divorciados, 21 vivem em união de facto, 13 vivem junto e por último, apenas 1 é viúvo. A maior parte da amostra, $70 \%$ não tem fillhos, $17,4 \%$ tem apenas um filho, $10 \%$ tem dois filhos e por fim $1,3 \%$ respectivamente para três e quatro filhos. A maioria da amostra, vive em meio urbano $(86,1 \%)$ e a restante $(13,9 \%)$ em meio rural, sendo a maioria residente na zona Norte $(36,1 \%)$ e Centro de Portugal (33,9\%).

Ao nível académico, 204 possuem mestrado, 21 doutoramento e 5 pré-Bolonha, a nível da área da formação, 187 apresentam formação em Psicologia Clínica e da Saúde, 23 em Psicologia da Educação, 17 em Psicologia do Trabalho e das Organizações e apenas $3 \mathrm{em}$ Psicologia Forense. De acordo com a especialização, 151 nomearam a Psicoterapia, 54 a Psicologia Comunitária, 13 a Psicologia Forense e por último apenas 12 a Neuropsicologia. Em relação ao exercício das suas funções, 169 participantes exercem há mais de 4 anos, representando $(73,5 \%)$ da população geral. Quanto aos anos de trabalho na organização, 194 participantes trabalham nas organizações há menos de 11 anos, apenas 3 trabalham há mais, 178 diz trabalhar para além do horário estipulado, representando $(77,4 \%)$ da amostra. Quanto ao regime de trabalho, 172 trabalha em regime de full-time, apenas 52 exerce funções em regime de parttime e 6 em outro regime. Ao nível da situação contractual, 75 participantes pertencem ao quadro efetivo, 71 exerce através da prestação de serviços, 49 apresentam vínculo precário/termo e 35 exercem através de outro tipo de contracto. Por fim, 139 participantes exercem funções em empresas até 50 trabalhadores, representando $(60,5 \%)$ da população. Os restantes 91 exercem funções em empresas com mais de 50 trabalhadores, representando $(39,5 \%)$ da geral.

\section{Resultados}

Foi testada a fiabilidade das escalas utilizadas através do Alpha de Cronbach que permite medir a consistência interna de uma escala. Os valores referentes ás subescalas "relaxamento" e "Procura de desafios", apresentaram valores de alfa, 0,83 e 0,82 , respetivamente, sendo descritos por Hill e Hill (2000) como bons. A subescala Afastamento Psicológico apresentou o alpha de 0,71 , sendo considerado um valor razoável, por último a subescala "Controlo" apresentou o alpha de 0,67, sendo classificado como um valor fraco. O "Questionário de Stress nos Profissionais de Saúde" é composto por 7 subescalas. A subescala relação com utentes apresentou o alpha de 0,79 , sendo considerado um valor razoável pelo 
mesmo autor. As subescalas relação com chefias e Excesso de Trabalho, apresentaram o alpha de 0,88 e 0,89 , respetivamente, sendo considerados valores bons. Com valores classificados como excelentes distinguem-se as seguintes subescalas Relação com Colegas, Carreira e Remuneração, Problemas Familiares e Condições de Trabalho, apresentaram valores de alpha, 0,91;0,90;0,95 e 0,92 , respetivamente.

No que se refere ao nível global de stress experienciado pelos psicólogos (as) na sua função, salienta-se o fato de $24,8 \%$ não descreveram problemas significativos neste nível (junção dos valores nenhum e pouco stress da escala likert), enquanto 47,8\% assinalaram níveis moderados. Para 27,3\% dos psicólogos (as), a sua profissão foi sentida como muito stressante (junção dos valores bastante stress e elevado stress da escala likert).

Em termos de fontes de stress (junção dos valores stress moderado, bastante stress e elevado stress da escala likert), as principais são: 187 profissionais apontam (1) a falta de possibilidade de desenvolvimento e promoção na carreira, representando $81,3 \%$ da amostra total, 183 apontam (2) a incompreensão face ao nosso trabalho por parte das pessoas a quem presto os meus serviços. (ex: clientes, cidadãos, etc.), 174 profissionais referem (3) a falta de perspectivas de progressão na carreira e por último 169 distinguem (4) O excesso de trabalho e/ou tarefas de carácter burocrático.

Em termos opostos (junção dos valores nenhum stress, pouco stress da escala likert), 117 apontam como nada/pouco stressante (1) conflitos e problemas com os colegas, representando $50,9 \%$ da amostra total, 113 referem-se (2) ao favoritismo e/ou discriminação encobertos no meu local de trabalho por parte dos meus superiores e por último 111 profissionais nomeam (3) os conflitos interpessoais com outros colegas de trabalho.

No que diz respeito às estratégias de enfrentamento (experiências de recuperação) (junção dos valores, concordo e concordo totalmente da escala likert), as principais são: 214 profissionais nomeiam (1) Procuro alargar os meus horizontes, representando 93,0 \% da amostra total, 213 nomeiam (2) Procuro tempo para desfrutar de momentos de lazer, 198 identificam (3) Aprendo coisas novas e por ultimo 190 apontaram (4) Sinto que sou capaz de decidir sobre aquilo que quero fazer".

Em termos opostos (junção dos valores discordo totalemente e discordo da escala likert), 189 profissionais apontam: (1) Não penso no trabalho de modo algum, representado $82,2 \%$ da amostra total, 140 nomeiam (2) esqueço-me do trabalho e por último 98 participantes referem-se a (3) distancio-me do trabalho.

Será estudado a direção e intensidade das relações/associações entre as variáveis em estudo. Segundo Bryman e Cramer (2003) através do modelo de regressão linear, o grande objectivo é avaliar se de facto na população algumas das variáveis independentes podem ou não influenciar a variável dependente, isto é, se o modelo ajustado é ou não significativo.

As variáveis dependentes correnpondem às subescalas das duas escalas utilizadas neste estudo. As variaveis independentes pessoais e profissionais selecionadas foram: Género; Idade; Número de Filhos; Formação Academica; Área de Formação; Trabalha para Além do Horário Estipulado e Dimensão da Organização. Tendo sido criadas as variáveis explicativas para o modelo, é então possível realizar a análise de regressão e testar as hipóteses da investigação.

Através dos resultados da análise de regressão, método Stepwise, foi testada a associação significativa entre a pergunta 1(Que sente geralmente no exercico da sua função?) e as variaveis independentes, com o objectivo de sabermos quais as preditoras dos niveis de stress geral. Através da análise verificamos que $6,8 \%$ dos niveis de stress é explicado pelas variaveis "Formação Académica" e "Trabalha para Além do Horário Estipulado", tal como demonstram os valores da tabela 1. Após a análise estatistica foi estudada a associação entre a variável dependente e as variaveis independentes. e de acordo com os valores da tabela 2 , o p-value $(\mathrm{Sig}=0,019$.) é inferior a 0,05 logo é possível concluir que pelo menos uma das variáveis independentes possui um efeito significativo sobre a variação da variável dependente.

Tabela 1

Resultados do SPSS resultante do processamento de regressão linear.

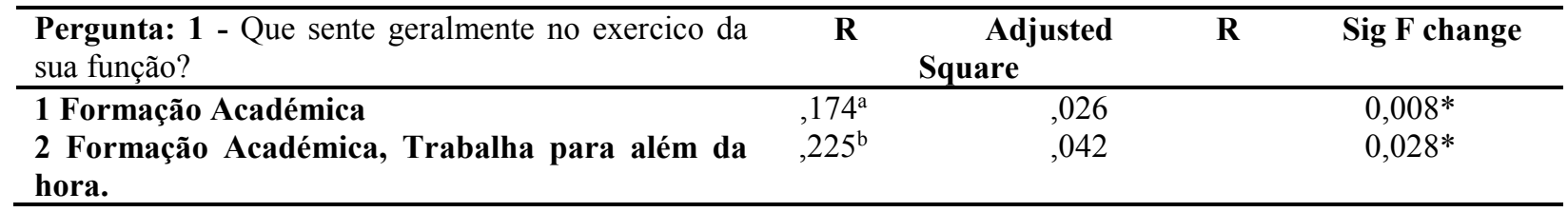

*Correlação significativa para um nível $<0,05$ 
Tabela 2

Resultados do SPSS resultante do processamento de regressão linear.

\begin{tabular}{|c|c|c|c|c|}
\hline "The Recovery Experience"(Relaxamento) & $R$ & $\begin{array}{c}R \\
\text { Square } \\
\end{array}$ & $\begin{array}{l}\text { Adjusted } R \\
\text { Square }\end{array}$ & $\begin{array}{c}\text { Sig } \\
\text { change }\end{array}$ \\
\hline 1 Número Filhos & $\underline{0,154^{\mathrm{a}}}$ & 0,024 & 0,020 & $0,019^{*}$ \\
\hline \multicolumn{5}{|l|}{$\begin{array}{l}\text { "The Recovery Experience"(Afastamento } \\
\text { Psicológico) }\end{array}$} \\
\hline $\begin{array}{l}1 \text { Trabalha para além do horário } \\
\text { estipulado }\end{array}$ & $0,145^{\mathrm{a}}$ & 0,021 & 0,017 & $0,028^{*}$ \\
\hline
\end{tabular}

Tabela 3

Regressão Linear das variáveis independentes em função da variável dependente.

\begin{tabular}{cccc}
\hline \multicolumn{4}{c}{ Variaveis independentes em função da variável dependente } \\
\hline Variáveis independentes & \multicolumn{2}{c}{ (Que sente } & geralmente no exercico da sua função?) \\
Subescalas & Pearson Correlation & Sig F change & $R$ \\
\hline "Relaxamento" & $-0,171$ & 0,009 & 0,171 \\
"Procura de desafios" & $-0,098$ & 0,069 & - \\
"Afastamento Psicológico" & $-0,248$ & 0,000 & 0,248 \\
"Controlo" & $-0,183$ & 0,003 & 0,183 \\
\hline *Correlação significativa para um nível $<0,05$
\end{tabular}

*Correlação significativa para um nível $<0,05$

A variável Número de Filhos é preditora representando cerca de $2,4 \%$ da variável dependente $\left(r^{2}=0,024\right)$. Através do valor de pearson $(\mathrm{p}=-0,154)$ podemos constatar que existe uma correlação negativa perfeita entre as duas variáveis - Isto é, se uma aumenta, a outra sempre diminui. Confirma-se que quanto maior for o número de filhos, menor serão as experiências de relaxamento.

As análises e os valores representados na tabela 2, provam que o afastamento Psicológico varia em função das horas de trabalho para além da hora, sendo que $14,5 \%$ do afastamento psicológico é explicado pela variável independente "Trabalha para além do horário estipulado". Através do valor de pearson $(\mathrm{p}=0,145)$ podemos constatar que existe uma correlação positiva entre as duas variáveis, isto é se uma aumenta a outra também aumenta. Confirma-se assim que quanto maior for o trabalho para além da hora, maior será o afastamento.

Através da análise dos resultados expostos na tabela 3, verifica-se que as variaveis independentes: relaxamento, afastamento psicológico e controlo relacionam-se inversamente com a variável dependente os niveis de stress. Não existe relação entre a variável procura de desafios e a variavel dependente. Sendo assim quanto maior forem as experiências de recuperação menor serão os niveis de stress, o mesmo acontece com as variaveis afastamento psicológico e controlo. A variável relaxamento explica $17,7 \%$ dos niveis de stress, no entanto o afastament explica $24,8 \%$ da variável dependente, a ultima variável controlo explica 18,3\%. Estes resultados corroboram as investigações de Sonnentag $(2011 ; 2012)$.

\section{Discussão dos Resultados:}

Faltam estudos que estabeleçam claramente as relações entre estas variáveis e que esclareçam melhor quais os fatores pessoais e profissionais que podem explicar as razões de alguns profissionais parecerem resistir melhor do que outros às adversidades laborais (Silva \& Gomes, 2009), nomeadamente com profissionais de Psicologia.

Esta investigação procurou responder aos 3 objetivos já mencionados. A maioria dos profissionais $(75,1 \%)$ classifica a sua função como acima do nível moderado de stress. Silva e Gomes (2009) afirmam que o valor médio de stress "elevado" em profissionais de Saúde em Portugal é de 40\%, nomeadamente em enfermeiros, médicos e psicólogos. Neste estudo apenas $3 \%$ classificou a sua função com "stress elevado", estando muito abaixo dos valores indicados pelos autores. Este resultado poderá estar relacionado com o facto da maior parte da população deste estudo ser do género feminino, por outro lado a investigação não foi direcionada apenas para uma área de especialização nem área de atuação. Sendo um assunto delicado, coloca-se em questão a total veracidade das respostas dadas pelos participantes, já que a recolha dos dados foi realizada online.

De acordo, com o primeiro objetivo, verificámos que as principais fontes de stress podem ser divididas e ordenadas respetivamente: (1) a falta de possibilidade de desenvolvimento e promoção na carreira; (2) a incompreensão face ao nosso trabalho por parte das pessoas a quem presto os meus serviços, (3) a falta de perspectivas de progressão na carreira e por ultimo (4) $\mathrm{O}$ excesso de trabalho e/ou tarefas de carácter burocrático. Estes resultados vão ao encontro de outras investigações, nomeadamente Ribeiro (2005) e Santos e Cardoso (2010) que salientam também o excesso de trabalho ou a escassez dele, o excesso ou défice de responsabilidades e progressão na carreira.

Um aspeto curioso diz respeito às situações que não preocupam de alguma forma os profissionais deste estudo, 
(1) conflitos e problemas com os colegas, (2) ao favoritismo e/ou discriminação "encobertos" no meu local de trabalho por parte dos meus superiores e por ultimo (3) os conflitos interpessoais com outros colegas de trabalho. Os resultados deste estudo vão ao encontro do estudo realizado por Gomes e Cruz (2004) com uma população de 439 Piscólogos de diversas áreas de formação e atuação.

O segundo objectivo é estudar as formas como estes profissionais recuperam após um dia de trabalho. A maioria da população afirma que procura alargar os seus horizontes e procuram tempo para desfrutar de momentos de lazer, por outro lado continuam a pensar no trabalho e não se esquecem do trabalho, ou seja é díficil distanciarem-se. O terceiro e último objectivo pretende avaliar as associações entre as experiências de recuperação e o stress ocupacional. Os resultados desta investigação comprovam que as subescalas Relaxamento, Afastamento Psicológico e o Controlo são preditoras dos niveis globais de stress. A literatura internacional diz-nos que das quatro dimensões apresentadas anteriormente, $o$ distanciamento psicológico é a primeira dimensão preditora significativa de uma forma recorrente (Sonnentag, et al., 2012; Sonnentag, 2011). Nesta investigação a subescala Distanciamento psicólogico apresenta o maior valor $(\mathrm{R}=0,248)$, explicando $24,8 \%$ da variável dependente. Constata-se na literatura internacional, que os autores tendem a relacionar a recuperação a inúmeros fatores (distanciamento psicológico; tensão; fatores pessoais; situações constrangedoras). No entanto, é evidente que identificam o stress como sendo o maior obstáculo de uma recuperação eficaz (Sonnentag \& Natter, 2004; Sonnentag, 2011).

Esta investigação permitiu conhecer, estudar e repensar as estratégias de recuperação a nível profissional, poderá contribuir para o desenvolvimento de estratégias de intervenção, que visem uma melhor recuperação e uma melhor qualidade de vida. A nível organizacional poderá tambem contribuir para futuros programas de intervenção e organização do trabalho.

Para melhor interpretação dos resultados desta investigação é importante serem consideradas algumas limitações metodológicas, sendo conveniente referir: a maioria da população é do género feminino, o que condiciona o estudo, nomeadamente no que diz respeito a comparações; outra limitação consiste em não avaliar o tipo de experiências/tarefas que as pessoas realizam ou nomeiam como forma de recuperação e a maioria da população pertencer á faixa etária (20 anos a 40 anos) indicando início de carreira profissional.

Desta forma, em futuros estudos seria pertinente saber e estudar as formas e novas formas das pessoas ocuparem os seus tempos livres com vista a recuperarem as energias. Seria importante relacionar os aspectos cognitivos/estratégias de coping e as condições de trabalho para se perceber as relações entre eles. A gestão de pessoas e o ambiente organizacional são factores interessantes como alvo de análise com vista à promoção da sáude e bem-estar quer pessoal quer organizacional.

Por último, a nível internacional a Agência Europeia para a Segurança e Saúde no Trabalho alerta para o facto de ter como objetivo elevar a qualidade das condições de trabalho. O artigo $151 .^{\circ}$ do Tratado sobre o Funcionamento da União Europeia estabelece que os Estados-Membros terão por objetivos a promoção do emprego e da melhoria das condições de trabalho, garantir a saúde e o bem-estar dos trabalhadores ao longo da sua vida profissional constituindo um pré-requisito para alcançar o objetivo da estratégia «Europa 2020» de aumentar o emprego em toda a UE. A nível organizacional, o mesmo organismo apesar das preocupações expressas, afirma que menos de um terço das organizações dispõem de procedimentos para prevenir esses riscos.

\section{Referências Bibliográficas}

Araújo, T. M, Graça, C.C, \& Araújo, E. (2003). Estresse ocupacional e saúde: contribuições do Modelo Demanda-Controle. Ciências e Saúde Coletiva 8 (4), 991-1003. Acedido em Novembro, 27, 2014, em: http://www.scielo.br/pdf/csc/v8n4/a21v8n4.pdf

Bicho, M., \& Pereira, R. (2007). Stress ocupacional. Acedido em Novembro 2, 2014, em:http://prof.santanasilva.pt/gestao_de_empresas/trab alhos 06 07/word/Stress $\% 20$

Canavarro, J.M.A.P. \& Oliveira, C. (2004). Psicologia Social Aplicada às Organizações. In Neto, Félix, Psicologia Aplicada (131-153). Lisboa: Universidade Aberta.

Costa, A.P.R. (2011). Hay vida más allá del trabajo: la relación entre la recuperación de recursos y el desempeño en el trabajo. Cádiz: Instituto de Formación interdiciplinar.

Demerouti, E. \& Bakker, A.B. (2011). The Job DemandsResources model: Challenges for future research. Journal of Industrial Psychology 37 (2), 1-9. Acedido em

Dezembro10,2014,em:http://www.beanmanaged.com/d oc/pdf/arnoldbakker/articles/articles_arnold bakker_24 5.pdf

Ferreira, J. M., Neves, J. \& Caetano, A. (2011). Manual da Psicossociologia das Organizações. Lisboa: Escolar Editora.

Franco, M. J. B. \& Tavares, E. P. (2009). Fontes de Pressão no Emprego e Seu Potencial na Qualidade Vida de Fisioterapeutas. Revista Lusófona de Ciências e Tecnologias de Saúde, 6 (2), 186-195. Acedido em Outubro 4, 2014, em: http://revistas.ulusofona.pt/index.php/revistasaude/artic le/view/1086/899

Fritz, C. \& Sonnentag, S. (2005). Recovery, Health and Job Performance: Effects of Weekend Experience. Journal of Occupational Health Psychology 10 (3), 187-199. Acedido em Outubro 4, 2014,em:http://www.researchgate.net/publication/7686 291 Recovery health and job_performance_effects_o f weekend experiences

Fritz, C. \& Sonnentag, S. (2006). Recovery, Well-Being, and Performance-Related Outcomes: The Role of Workload and Vacation Experiences. Journal of Applied Psychology 91 (4), 936-945. Acedido em Novembro 22, $2014 \quad$ em: http://www.researchgate.net/publication/6950127 Reco 
very wellbeing and performancerelated_outcomes th e role of workload and vacation experiences

Fritz, C., Sonnentag, S., Spector, P.E. \& McInroe, J. A. (2010). The weekend matters: Relationships between stress recovery and affective experiences. Journal of Organizational Behavior 31, 1137- 1162. Acedido em Novembro 2, 2014, em: http://www.researchgate.net/publication/228079796 T he weekend matters_Relationships_between_stress_re covery and affective experiences

Gomes, A.R. (2010). Questionário de Stresse Ocupacional - Versão Geral (QSO-VG). Relatório técnico não publicado. Braga: Universidade do Minho.

Gonçalves, S.P. (2014). Stress e bem-estar no trabalho. In S.P. Gonçalves, Psicossociologia do trabalho e das Organizações: Princípios e Práticas (173-231). Lisboa: Pactor.

Innstrand, T. S, Langballe, M. E, \& Falkum, E. (2011). A Longitudinal Study of the Relationship between Work Engagement and Symptoms of Anxiety and Depression. Stress and Health, 28, 1-10 Acedido em Dezembro 7, 2014, em: http://onlinelibrary.wiley.com/doi/10.1002/smi.1395/pd f

Kazmi, R., Amjad, S., \& Khan, D. (2008). Occupational Stress and its effect on Job Performance: A case study of medical house officers of district Abbotabad. Journal of Ayub Medical College, 20 (3), 135-139. Acedido em Setembro 1, 2014, em: http://ayubmed.edu.pk/JAMC/PAST/20-3/Rubina.pdf

Kuhnel, J. \& Sonnentag, S. (2010). How Long Do You benefit From Vacation? A Closer Look at the Fade-Out of Vacation Effects. Journal of Organizational Behavior 32, 125-143. Acedido em Novembro 2, 2014, em:

http://www.researchgate.net/publication/229943851 H ow long do you benefit from vacation_A_closer lo ok at the fadeout of vacation_effects

Laranjeiras, C. A. (2009). O Contexto Organizacional e a Experiência de Estress: uma Perspetiva Integrativa. Revista de Salud Pública, 11 (1), 123-133. Acedido em Outubro 15, 2014, em: http://www.scielosp.org/pdf/rsap/v11n1/v11n1a13

Machado, G., Porto-Martins, C., \& Amorim, C. (2012). Engagement no trabalho entre profissionais da educação. Revista Inter saberes 7 (13), 193-214. Acedido em Dezembro 10,2014,em:http://grupouninter.com.br/intersaberes/ind ex.php/revista/article/view/257/166

Malta, J (2015). Stress faz empresas Portuguesas perderem 300 milhóes por ano . Sapo informação (web site). Acedido em Abril 1,2015,em:http://rr.sapo.pt/informacao_detalhe.aspx?fi $\mathrm{d}=24 \& \mathrm{did}=181292$

Neves, J. (2014). Psicologia Organizacional: individuo, trabalho e organização. In S.P. Gonçalves, Psicossociologia do trabalho e das Organizações: Princípios e Práticas (173-231). Lisboa: Pactor.

Rodrigues, P.F., Álvaro, A.L.T. \& Rondina, R. (2006). Sofrimento no trabalho na visão de Dejours. Revista eletrónica de Psicologia 4 (7), 1-8. Acedido em
Outubro

15 , 2014,em:http://faef.revista.inf.br/imagens arquivos/arq uivos destaque/lh21p1iEajxlWcK 2013-5-10-15-302.pdf

Salanova, M. (2012). A Special Issue on Work Engagement. Ciencia \& Trabajo, 14, 1-90. Acedido em Outubro 15, 2014, em: http://issuu.com/cienciaytrabajo/docs/work_engagemen $\underline{\mathrm{t}}$

Seabra, A.P.P.C (2008). Síndrome de Burnout e a Depressão no Contexto de Saúde Ocupacional. Tese de Doutoramento, Instituto de Ciências Biomédicas Abel Salazar - Universidade do Porto.

Serra, A. V. (2002). O stress na vida de todos os dias. Coimbra: Autor.

Serra, A. V. (2011). O Stress na vida de todos os dias $\left(3^{\mathrm{a}}\right.$ ed.). Coimbra: Dinalivro Distribuidora Nacional de Livros, Lda.

Sonnentag, S. \& Bayer, U. (2005). Switching off Mentally: Preditors and consequences of psychological Detachment from Work During Off-Job Time. Journal of Occupational Health Psychology 10 (4), 393-414. Acedido em Novembro 2, 2014, em:http://www.researchgate.net/publication/7517316_S witching_off_mentally_predictors and consequences of psychological detachment from work during offjob time

Sonnentag, S. \& Fritz, C. (2007). The recovery Experience Questionnaire: Development and Validation of a measure for Assessing Recuperation an Unwinding from Work. Journal of Occupational Health Psychology 12 (3), 204-221. Acedido em Outubro 2014,em:http://www.researchgate.net/publication/6201 016 The Recovery Experience Questionnaire develo pment and validation of a measure for_assessing_re cuperation and unwinding from work

Sonnentag, S. \& Zijlstra, F. (2006). Job Characteristics and Off-Job Activities as Predictors of Need for Recovery, Well-Being, and Fatigue. Journal of Applied Psychology 91 (2), 330-350. Acedido em Novembro 1, 2014,

em: http://www.researchgate.net/publication/7228188 Job characteristics_and_offjob_activities_as predictors_of need for recovery well-being and fatigue

Vaz-Serra, A. (2005). As Múltiplas facetas do Stress. In A. Pinto \& A. Silva, Stress e Bem-estar: Modelos e domínios de aplicação (17-42). Lisboa: Climepsi

Vaz-Serra, A. (2007). O stress na vida de todos os dias. $3^{\mathrm{a}}$ Edição. Minerva Coimbra 